\title{
Dark Pools And Flash Orders: The Secret World Of Automated High-Frequency Trading
}

\author{
Chris Rose, Walden University, USA
}

\begin{abstract}
A market should be the purest form of exchange with willing buyers and sellers, with perfect information, agreeing on a price for a stock or commodity. Unfortunately, there are sophisticated computer systems sometimes located in the very building that house the stock or commodity exchange servers, and those computers can execute millions of trades per second. Those computers are even allowed to secretly view available trades before the rest of the general public and sometimes those trades are even clandestinely made, without any broadcast of the buy or sell prices to others. What is clear is that far from being a pure form of exchange, today's market is heavily skewed, with the average consumer being the loser.
\end{abstract}

Keywords: Stock Markets, Trading, Dark Pools, Flash Orders, High Frequency Trading

\section{INTRODUCTION}

tis generally agreed that the first organized stock exchange was created in 1792 at Wall Street, New York,
when a small group of financial leaders signed an agreement on fees, rules and regulations that would apply
in transactions. Each day securities were auctioned and the seller paid a commission on each stock or bond sold. These trades took place in a free and open market where willing buyers and sellers assembled and freely exchanged goods, services and information. Wall Street grew in size and importance but for most of its history, stock trading was a straightforward transaction where buyers and sellers gathered on the exchange floors and bargained until they arrived at a compromise acceptable to all.

However, in 1998, the Securities and Exchange Commission (SEC) authorized the formation of electronic exchanges, the idea being to open markets so that anyone with a computer could compete with established markets such as the New York Stock Exchange (NYSE). This type of exchanges, called an electronic communication network (ECN) account for an increasing large volume of shares and commodities traded daily. In fact, very few people have ever heard of the third largest exchange in the world (behind NYSE and NASDAQ) called the BATS Exchange mainly because BATS is a purely high-tech electronic exchange.

Only about $3 \%$ of the trading volume on the NYSE is done by means of traditional trading, where actual traders gather on the floor of the exchange to buy and sell securities. The other 97\% of NYSE trades are executed on ECNs, which in the last decade have quickly replaced traders, trading on floors as the main global venue for buying and selling every asset, derivative, and contract. Therefore, the ECNs are the markets today and all those pit traders who pose for the cameras are mainly there just for the cameras (Stokes, 2009a).

\section{HIGH-FREQUNCY TRADING}

High-Frequency Trading (HFT) has remained in the shadows and yet HFT accounts for the majority of trading in stocks, commodities and futures in the United States today. For example, HFT firms, only account for approximately $2 \%$ of the 20,000 or so trading firms that operate in U.S. markets today, but this $2 \%$ account for $73 \%$ of all U.S. equity trading volume with aggregate annual profits of $\$ 21$ billion. "These companies include proprietary 
trading desks for a small number of major investment banks, less than 100 of the most sophisticated hedge funds and hundreds of the most secretive prop shops, all of which operate with one thing in mind - capture profit opportunities by being smarter and faster than the closest competition" (Iati, 2009).

These HFTs would perhaps have remained hidden, but for Sergey Aleynikov, a Russian programmer and employee of Goldman-Sachs, who was arrested by the FBI in July 2009 for stealing 32Mbyte of compressed files, the trading algorithm belonging to Goldman-Sachs. The data was uploaded to a server in Europe and of course was leaked on to the Internet. At the beginning of June, Aleynikov ran scripts using a bash shell to copy and compress a large amount of source code. After the compression, he sent it to the servers through a secure server protocol to a server in Germany. He sent about 32Mbyte in ASCII code about four times." (Chowdhry, 2009) Aleynikov tried to cover his tracks by having the script erase his history, but Goldman's machines kept a backup of everyone's history, which seem to have set off an alarm, which caused further investigation.

These sophisticated trading platforms use a combination of proprietary, secret algorithms and the fastest hardware available. They absorb and analyze massive amounts of market data and news and generate millions of trades timed to the millisecond. "So, instead of operating on the old stock market adage, "buy on the rumor, sell on the news," a high-frequency trading platform like Goldman's will buy a few milliseconds after the news hits, then sell moments later at a very small premium to other traders and platforms who didn't get the news in (or their trades out) quite as fast. Do this billions of times a day, and voila, you're printing money." (Stokes, 2009b)

These HFTs are smart, adapt quickly and are extremely secretive (and prefer to stay that way) and are relatively unknown. The key to their being smarter and profitable is their unique technology that enables them to profit on a number of strategies, which they will protect at all costs. Their incredible capabilities have allowed a relative few HFT firms to now wield far greater influence on the markets today than most people recognize (Iati, 2009). Some of these HFT firms - such as Getco, Peak6, RGM Advisers and Hudson Bay Trading - are far from household names in the markets and many are based in Chicago. (Grant, 2009)

\section{FLASH ORDERS}

Flash orders, whereby orders are shown to members of an exchange for a split second before being passed on to the wider market, have become an integral part of HFT. To avoid signaling their intentions to the market, institutional investors trade large orders in small blocks - often in lots of 100 to 500 shares - and within specified price ranges. High-frequency traders attempt to uncover how much an investor is willing to pay (or sell for) by sending out a stream of probing quotes that are swiftly cancelled until they elicit a response. The traders then buy or short the targeted stock ahead of the investor, offering it to them a fraction of a second later for a tiny profit. Highfrequency traders may execute 1,000 trades per second; exchanges can process trades in less than 500 microseconds. (Grant, 2009)

An example given by the New York Times (Figure 1) aptly demonstrates the problem. On July 15, (Intel had reporting strong earnings the night before) investors saw an opportunity and decided to buy shares in Broadcom, the semiconductor company. The slower traders had a problem; if they bought a large number of shares at once then everyone would know and Broadcom's shares would rise. Therefore, they decided to divide their orders into dozens of small batches, with the intent of keeping their plans secret. At the market open, shares of Broadcom started trading at $\$ 26.20$.

Markets are thought to be transparent and equitable by showing orders to everyone at the same time but a loophole in regulations allows exchanges to show HFTs some orders ahead of everyone else for a fee. The slower traders began buying but because of flash orders, instead of orders being shown to all potential sellers at the same time, some of those orders were sent to HFTs for just 30 milliseconds ( 0.03 seconds). In less than half a second, HFTs gained an advantage and knew there was demand for Broadcom so their automated systems began buying Broadcom shares and then reselling them to the slower investors at higher prices.

This pushed the price of Broadcom shares higher. Soon, there were thousands of orders as HFT systems began trading. "Automatic programs began issuing and canceling tiny orders within milliseconds to determine how 
much the slower traders were willing to pay. The high-frequency computers quickly determined that some investors' upper limit was $\$ 26.40$. The price shot to $\$ 26.39$ and high-frequency programs began offering to sell hundreds of thousands of shares" HFTs often confuse other investors by issuing and then canceling orders almost simultaneously. Since they can get an early glance at how others are trading and their powerful computers can essentially force slower investors into giving up profits, then the HFTs disappear before the other traders even knows they were there (Duhigg, 2009). The unfairness of this system is causing serious concern and the SEC is investigating the practice of sending these electronic messages on to the trading platform to "test" the likelihood of an incoming order finding a match in it - so-called "indications of interest"(Grant, 2009).

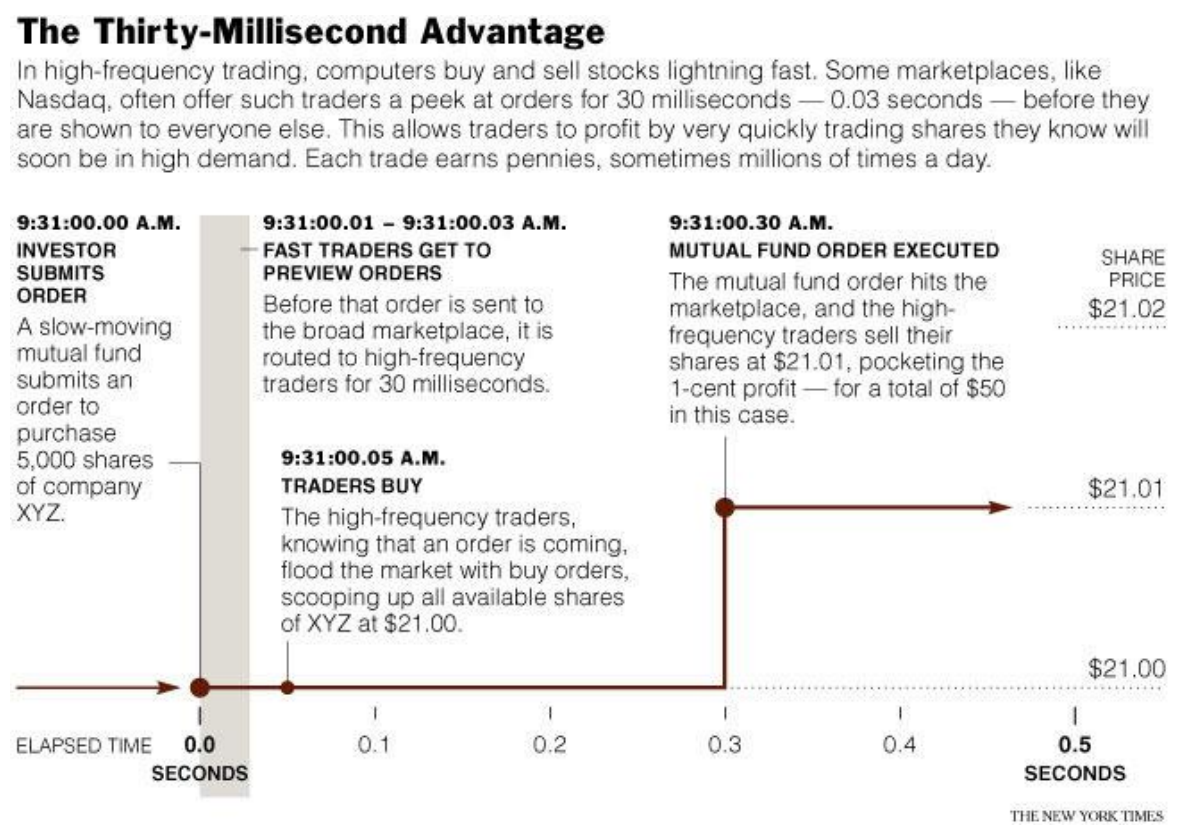

Figure 1: (The New York Times)

A couple of years ago if an investor placed a limit order for $\$ 26.40$ when the market was at $\$ 26.10$, the odds were excellent that most of the order would have filled near where the market was when they entered the order i.e. at $\$ 26.10$. However, today the odds are excellent that most of their order will fill at $\$ 26.39$ because of HFTs and yet the HFT firms will claim this is what creates an efficient market. "The truth is that you got screwed for 29 cents per share which was quite literally stolen by the HFT firms that probed your book before you could detect the activity, determined your maximum price, and then sold to you as close to your maximum price as was possible" (Denninger, 2009). They deliberately probed the market with very small orders that were immediately canceled in order to gain an illegal advantage and determine the price the buyer was willing to pay.

With normal order queues and flows the person with the limit order would see the offer at $\$ 26.20$ and might drop his limit. "But the computers are so fast that unless you own one of the same speed you have no chance to do this - your order is immediately "raped" at the full limit price! You got screwed, as the fill price is in fact 30 cents a share away from where the market actually is" (Denninger, 2009).

Another popular HFT strategy is to collect rebates that exchanges offer to liquidity providers. Highfrequency traders will quickly outbid investors before immediately selling the shares to the investor at the slightly higher purchase price, collecting a rebate of one-quarter of a cent on both trades. Other tactics include piggybacking on sharp price movements to increase volatility, which increases the value of options held by traders (The Economist, May 2009). 


\section{DARK POOLS}

The SEC has been looking into flash orders as part of a review of what are called "dark pools" - electronic trading venues that do not display public quotes for stocks. Dark pools are supposed to be used to trade large blocks of shares, with prices posted publicly only after trades are done (Grant, 2009). Bigger investors are moving to "dark pools", where orders are anonymously matched so that traders do not alert the wider market to their intentions. Obviously, this means that stock pricing is not transparent and yet dark pools accounted for $9 \%$ of the US market in 2008 .

If a HTF wants to find out what a dark pool will either buy or sell and at what price, the HFT first has to send a query to it by pinging it. For instance, suppose the HFT pings the dark pool with a request to buy a specific asset, the pool will reply with the price at which it is willing to sell that asset. The HFT can either accept the price and complete the transaction, or turn it down and try again later to see if the price has moved in their direction. Dark pools, then, let traders completely sidestep normal stock and commodities exchanges in order to buy and sell assets without having to broadcast their desired price to the rest of the world (Stokes, 2009c).

\section{THE SOFTWARE}

It is estimated that up to $75 \%$ of the NYSE's daily trading volume is comprised of one computer just trading against one another using a number of sophisticated strategies, which make up a lively ecosystem of algorithms, or "algos" as they are called, that use ECNs in different ways to make money. These algos are not longterm, classic buy-and-hold long-term strategies but instead they aim to execute as many trades per second as possible while making a small profit, sometimes as small as pennies or fractions of a penny, on each trade. However, because of extremely high speed, and massive volume these small per trade profit quickly add up. Jon Stokes identifies two main classes of algos, iceberging and predatory algos, and statistical arbitrageurs.

Iceberging is the breaking up of large orders into small orders of random size to disguise the fact that they have a very large stock order trading. This is done to prevent other traders from sensing that a large order is about to take place and might do something to affect the stock price. The other traders would be using their predatory algos whose job it is to monitor the market to try and detect these types of large hidden orders. For example, a predatory algo might determine that someone is trying to hide a large order of a certain stock by sending it out in small amounts of varying sizes. The predatory algo would attempt to bid down that stock just so that it can turn around and buy the stock and sell it back shortly afterwards when the stock goes back to its normal value.

Another type of algo that Stokes identified was the statistical arbitrageur (stat arb). The stat arb goes through huge volumes of data looking for correlations between various datapoints and asset prices. The stat arb uses those correlations to build a predictive model that will take into account any new information such as news reports and stock prices and then creates a steady stream of buy and sell orders for different assets. For example, Steve Jobs is intrinsically linked to the price of Apple stock, so a stat arb might create a predictive model about the health of Steve Jobs and the price of the stock. News services feed these HFTs with a steady stream of news so within a fraction of a second of a news report that Steve Jobs has passed his latest physical, the stat arb will immediately create multiple buy orders and sell back as soon as this news becomes known to the rest of the general public.

The stat arb does not have to be correct all the time, they just have to be right the majority of the time to make money from the thousands of trades they do each day, and this requires high speed and good correlations. The stat arb has to process information as quickly as possible and make orders to the exchange as rapidly as possible to in order to beat their competition. Another HFT might very well be using a similar stat arb and similar computer hardware, so getting the trade completed microseconds before their competitor will allow them to make a penny or two more on that trade. The other important factor is to be able to quickly find new correlations if the correlations they are working with stop holding true and since the amount of money involved is so massive, hiring a few dozen $\mathrm{PhD}$ programmers to constantly monitor these algos is a very small investment. 


\section{THE HARDWARE}

High-frequency traders are involved in an arms race, the arms being computers, graphic cards and computer throughput, so this results in a cycle of spending which leaves everyone in the same relative position, only poorer. The HFTs are the ones supporting the microprocessor manufactures on the cutting edge and according to Intel, trading houses can make a substantial amount of money just by moving up on speed bin, (from say 3.2 to 3.4 $\mathrm{GHz}$ ) because this puts them a few microseconds ahead of the other trader. "The various financial firms who had to be as fast as everyone else then shelled out an aggregate of hundreds of millions of dollars to upgrade, so that they could now execute trades in thirty milliseconds rather than forty milliseconds... and now there is a new chip, code named Nehalem. So another hundred million dollars all around, and latency will be dropped a few milliseconds more (Bookstaber, 2009).

Throughput and latency are also important in HFT with the standard tricks being "to get your servers as close to the data source as possible, use really big lines, and break data into little bite-sized packets. I was speaking at Reuters last week, and they mentioned to me that they were breaking their news flows into optimized sixty-byte packets for their arms race-oriented clients, because that was the fastest way through network. (Anything smaller gets queued by some network algorithms, so sixty bytes seems to be the magic number)" (Bookstaber, 2009).

The other key ingredient to the success of any HFT platform is low network latency. These HFT platforms are assisted by the fact that many exchanges will let HFT platforms pay to co-locate their servers in the same building as those of the exchange itself, so that the HFT platform can get its order in ahead of the competition. Some contend that co-location deals are just another way to allow an HFT platform to get an advance look at an incoming order and then use that knowledge to make a quick bet on the impending price move to make a profit.

\section{CONCLUSION}

The intent behind the introduction of ECNs so that anyone with a computer would have access to trading might have been good, but high-frequency traders have exploited the technology to their advantage. With powerful computers costing millions of dollars, a bevy of $\mathrm{PhD}$ programmers on payroll creating sophisticated algorithms and with loopholes in the regulations, HFTs are assured of a profit every day. They see orders before the general public, they place and withdraw orders before they are filled to see the response, and sometimes they even make trades that are not broadcast to the general public. With their servers in the same buildings as the exchange servers they have the ultimate advantage. Even if two traders had the same algorithms and computing power, there could never be equitable trading if one trade has to travel thousands of miles and the other, by arrangement, just has to travel a hundred feet. With only the SEC as an arbiter in between the HFTs virtually minting money and the public being bilked out of money in each trade, the average consumer is obviously the loser, and this imbalance has to be corrected since dark pools and flash orders hide the secret world of high-frequency trading..

\section{AUTHOR INFORMATION}

Dr. Chris Rose received an MBA in Management, an MS in Information Systems, a Doctorate in International Management and a Doctoral Specialization in Information Technology Management all from Nova Southeastern University, Ft. Lauderdale, Florida, from both the Graduate School of Computer and Information Sciences and the H. Wayne Huizenga School of Business and Entrepreneurship. He is the President of Technology Research Institute of Florida, Inc. His current area of interest is virtual proctoring of examinations in distance education using streaming media and biometric identification.

\section{REFERENCES}

1. Bookstaber, R. (2009, April 21) The Arms race in High Frequency Trading. Retrieved on August 22, 2009 from http://rick.bookstaber.com/2009/04/arms-race-in-high-frequency-trading.html

2. Chowdhry, A. (2009, July) Goldman Sachs Algorithms Stolen By Sergey Aleynikov Now Leaked On The Internet. Pulse2. Retrieved August 23, 2009 from http://pulse2.com/2009/07/08/goldman-sachs-algorithmsstolen-by-sergey-aleynikov-now-leaked-on-the-internet/ 
3. Denninger, K. (2009, July 24) High Frequency Trading Is A Scam. The Market Ticker. Retrieved August 21, 2009 from http://market-ticker.denninger.net/archives/1259-High-Frequency-Trading-Is-A-Scam.html

4. Duhigg, C. (2009, July 23) Stock Traders Find Speed Pays, in Milliseconds. The New York Times. Retrieved August 18, 2009 from http://www.nytimes.com/2009/07/24/business/24trading.html

5. Grant, J. (2009, July 10) 'Secretive' firms dominate US share trading. FT.com. Retrieved August 19, 2009 from http://www.ft.com/cms/s/a5f03366-6d69-11de-8b19-

00144feabdc0,Authorised=false.html?_i_location=http $\% 3 \mathrm{~A} \% 2 \mathrm{~F} \% 2 \mathrm{Fwww} . f t . c o m \% 2 \mathrm{Fcms} \% 2 \mathrm{Fs} \% 2 \mathrm{~F} 0 \% 2 \mathrm{~F}$ a5f03366-6d69-11de-8b19-00144feabdc0.html\%3Fnclick_check\%3D1\&_i_referer=\&nclick_check=1

6. Iati, R. (2009, July 10) The Real Story of Trading Software Espionage. Advanced Trading. Retrieved August 19, 2009 from http://advancedtrading.com/algorithms/showArticle.jhtml?articleID=218401501\#undefined

7. Konczal, M. (2009, Jul 28) How to Understand High Frequency Trading. The Atlantic. Retrieved August 20, 2009 from http://business.theatlantic.com/2009/07/water_cooler_guide to high frequency trading.php

8. Stokes, J. (2009a, April 22) Why high-performance computing needs financial engineering. Ars Technica. Retrieved August 19, 2009 from http://arstechnica.com/business/news/2009/04/why-processors-need-highfinance.ars

9. Stokes, J. (2009b, July 7) Goldman's secret sauce could be loose online; markets beware. Ars Technica. Retrieved August 19, 2009 from http://arstechnica.com/tech-policy/news/2009/07/goldmans-secret-saucecould-be-loose-online-markets-beware.ars

10. Stokes, J. (2009c, July 27) The Matrix, but with money: the world of high-speed trading. Ars Technica. Retrieved on August 19, 2009 from http://arstechnica.com/tech-policy/news/2009/07/-it-sounds-likesomething.ars

11. The Economist. (2009, July 30) Rise of the machines. The Economist print edition. Retrieved August 20, 2009 from http://www.economist.com/businessfinance/displaystory.cfm?story_id=14133802 